\title{
Occurrence and effects of octreotide antibodies during nasal, subcutaneous and slow release intramuscular treatment
}

\author{
Andreas Kaal ${ }^{1,2}$, Hans Ørskov ${ }^{1}$, Steen Nielsen ${ }^{1}$, Alberto M Pedroncelli ${ }^{3}$, Ioana Lancranjan ${ }^{4}$, Peter Marbach $^{4}$ \\ and Jørgen Weeke ${ }^{2}$ \\ ${ }^{1}$ Institute of Experimental Clinical Research, University of Aarhus, Denmark, ${ }^{2}$ Department of Endocrinology and Diabetes, \\ Aarhus University Hospital, Denmark, ${ }^{3}$ Endocrine Unit, Ospedali Riuniti, Bergamo, Italy and ${ }^{4}$ Novartis Pharma, Basle, Switzerland \\ (Correspondence should be addressed to A Kaal, Medical Research Laboratories, Aarhus Kommune Hospital, Nørrebrogade 44, \\ DK-8000 Aarhus C, Denmark; email: AA@AFDM.au.dk)
}

\begin{abstract}
Objective: Previous studies have indicated that antibody formation against octreotide is extremely rare. We examined the occurrence of octreotide antibody formation after treatment with three administration forms in large populations of patients with acromegaly or carcinoid syndrome. Design: (i) Nasally administered octreotide: 70 previously untreated patients and 81 previously s.c. octreotide-treated patients participated. (ii) Subcutaneously administered octreotide: 172 acromegalic patients and 59 patients with carcinoid syndrome treated for up to 12 years participated. (iii) Intramuscularly administered depot octreotide (Sandostatin LAR): 62 acromegalic patients participated.

Methods: Presence of antibodies is defined as increased precipitation by polyethylene glycol of ${ }^{125} \mathrm{I}-$ octreotide after incubation with serum; this was also used for screening of cross-reaction with somatostatin and lanreotide (Somatuline).

Results: In patients who received nasal octreotide for at least 9 and up to 12 months $(n=42)$, the occurrence of octreotide antibodies was $77 \%$ and $81 \%$ for previously untreated and treated patients respectively. In subcutaneously treated patients it was 63/231 (27\%) after a mean exposure of 3 years. In patients treated for more than 5 years $(n=53)$ it was $57 \%$ and after 8 years $(n=18) 72 \%$. In contrast, no patient could with certainty be identified to be antibody-positive after a mean of 2.5 years intramuscular Sandostatin LAR treatment $(n=47)$. In all populations, the antibody-positive patients were as well controlled as the antibody-negative patients. Octreotide antibodies did not cross-react with native somatostatin $(n=141)$, while about $25 \%$ of the antibody-positive sera did cross-react with the somatostatin analogue, lanreotide (Somatuline, Ipstyl, Angiopeptin).

Conclusions: Antibody formation against octreotide is much more frequent than previously believed. It depends primarily on drug exposure time and route of administration. It does not alter the GH/IGF-I status in treated acromegalic patients and induces only mild local reactions in some patients.
\end{abstract}

European Journal of Endocrinology 143 353-361

\section{Introduction}

Antibody formation against exogenous hormones has been well known for several decades (1-3) and is best studied for insulin. More than 40 years research in this field has shown no ill effects except for very rare cases of insulin resistance and allergy and occasional local skin manifestations at injection areas (4).

Eight cases have until now been published of antibodies developing against octreotide during subcutaneous administration; this occurred within 4 years of treatment (5-8). In view of the fact that several hundred patients have been in prolonged treatment with octreotide since it was introduced in 1985, the incidence appears to be low using the subcutaneous route. Only 2 studies comprising 20 patients have been carried out specifically looking for octreotide antibodies using acceptable specific analyses, and none was found in patients treated for up to 3 years $(9,10)$. However, as the presence of antibodies was symptomless in the 2 patients we originally described, we supposed that the true incidence may be higher (6).

The present study has validated a simple precipitation technique for identifying antibodies against octreotide in large populations of patients with acromegaly and carcinoid syndrome, and it has been used for the evaluation of the effects on octreotide efficacy as well as for establishing the incidence and time course of 
antibody development during treatment with three different octreotide formulations.

\section{Materials and methods}

\section{Patients}

Nasal application (study 1) In the present study, we investigated if and when serum octreotide antibodies appeared during at least 28 and up to 360 days of treatment with octreotide given by nasal application. The population consisted of 70 acromegalic patients who according to the study protocol had never been treated with octreotide before, and 81 patients who had already been on subcutaneous treatment for up to 8 years.

The previously untreated patients received $0.25 \mathrm{mg}$ t.i.d. nasal octreotide after study entry, doubling the dose every 14 days up to $2 \mathrm{mg}$ t.i.d. If the 8 -h mean serum growth hormone (GH) level remained at $<5.1 \mu \mathrm{g} / \mathrm{l}$ the patient continued on the dose. From day 42 to day 182 the dose was maintained constant. After day 182 the patients were treated according to their status. The patients were admitted at days $2,15,29,43$, $90,182,274,360$ and 362 for insulin-like growth factor-I (IGF-I) determination and 8-h serum GH profiles. These determinations were performed in our laboratory, which functioned as the central laboratory of the multicentre trial.

All previously treated patients were selected according to the study protocol and included only those patients who had an average $8-\mathrm{h} \mathrm{GH}<5 \mu \mathrm{g} / \mathrm{l}$ on $100 \mu \mathrm{g}$ s.c. octreotide t.i.d. The study was double blind for six months, with the patients randomized to receive 0.25 , 0.5 or $1 \mathrm{mg}$ t.i.d. octreotide by intranasal insufflation or $100 \mu$ g t.i.d. subcutaneously (controls). From days 182 to 360 the patients were in an open-label extension study treated according to their status and received only exceptionally the $2 \mathrm{mg}$ dose. It was planned that all controls on s.c. octreotide should be switched to nasal octreotide at the end of the double-blind study. For the statistical evaluation, all controls who never switched to the nasal treatment were excluded. The patients were admitted on day -14 (screening on s.c. octreotide), day 0 (after a 3-14 days washout period), and days 14, 28, $56,84,182,274$ and 360 for 8 -h serum GH profiles and IGF-I determination. All patients who already harboured octreotide antibodies at study entry (previous s.c. treatment) were excluded and were taken into account in study 2 .

For both groups local nasal effects were evaluated by a rhinoscopic examination of the nasal cavity and an assessment of the sense of smell at each visit by an ear, nose and throat specialist.

The nasal formulation was in clinical use only in 1992-1994 and it was abandoned by Sandoz due to 'suboptimal' local tolerability, even though efficacy and systemic tolerability were adequate.
Subcutaneous treatment (study 2) The occurrence of octreotide antibodies in patients on subcutaneous octreotide treatment lasting at least 3 months and up to 12 years was studied in serum samples from 38 acromegalic patients in our clinic, 116 acromegalic patients who were screened for participation in the European nasal multicentre trial, 18 Italian acromegalic patients before entering a European multicentre study with Sandostatin LAR and 59 patients with carcinoid syndrome before entering a US multicentre trial with Sandostatin LAR.

Slow release octreotide (study 3) The occurrence of antibodies in 47 acromegalic patients (from Romania $(n=24)$, Italy $(n=12)$, Denmark $(n=7)$ and UK $(n=4))$ after up to 3 years treatment with Sandostatin LAR was studied. The patients from Italy, UK and Denmark had previously been treated with subcutaneous octreotide for a longer period (mean exposure time \pm s.E.M.: $34 \pm 7$ months, data not available for 4 patients), but did not harbour detectable antibodies at study entry. To avoid problems implicit in using previously long-term treated patients, twenty-four Romanian patients who had only a 2-week s.c treatment period prior to LAR were also included. In 13 of them we were able to study washout samples (taken 62 days after their last LAR injection). For the remaining 11 patients we received samples collected about 3 months after termination of the LAR study, the patients being treated meanwhile with s.c. octreotide.

Furthermore, we studied retrospectively sera from 15 acromegalic patients who already harboured octreotide antibodies before study entry (i.e. attained during previous intranasal or subcutaneous administration) with special reference to efficacy and (local and systemic) tolerability.

All the different studies were approved by the local ethics committees, and written informed consent was obtained from the patients.

\section{Assays}

GH analyses were performed during 6- to 8-h GH profiles (one sample per hour) and analysed consecutively by a commercial non-competetive time-resolved immunofluorometric human (h) GH assay (TR-IFMA, Delfia, Wallac, Finland) using two monoclonal antibodies directed against different sites of the $22 \mathrm{kDa}$ variant of hGH.

Total IGF-I was determined (in fasting morning samples before drug administration) by an in-house TR-IFMA after acid-ethanol extraction of serum, as described previously (11).

Screening for octreotide antibodies was performed retrospectively and prospectively in fasting serum samples taken just before administration of the morning nasal or subcutaneous dose or in the first sample from washout days. 
Presence of octreotide antibodies is defined as a precipitation of iodinated octreotide $\left({ }^{125} \mathrm{I}_{\text {-DTyr }}{ }^{1}\right)$-octreotide, ANAWA, Wangen, Switzerland) diluted in $200 \mu \mathrm{l}$ phosphate buffer with $\mathrm{NaN}_{3} 0.05 \%, 40 \mathrm{mmol} / \mathrm{l}$, pH 8.0), (10 000 c.p.m.), which had been incubated in triplicate with $30 \mu \mathrm{l}$ serum samples at $4{ }^{\circ} \mathrm{C}$ for $48 \mathrm{~h}$, greater than the average percentage precipitation attained in 7 control sera plus 3 s.D., using addition of $100 \mu \mathrm{l}$ new-born calf serum (to facilitate gammaglobulin precipitation) and then $1.8 \mathrm{ml} 20 \%$ polyethylene glycol (PEG 6000 in phosphate buffer $40 \mathrm{mmol} / \mathrm{l}$, $\mathrm{pH} 8.0$ ) with $0.5 \%$ Tween 20 (both Merck, Darmstadt, Germany) and centrifugation (3600 r.p.m. at $4{ }^{\circ} \mathrm{C}$ for $18 \mathrm{~min}$ ). This method relies on precipitation of large proteins (molecular mass greater than approximately $70 \mathrm{kDa}$ ) and is therefore not specific for gammaglobulins. However, PEG has been used for decades in RIA for precipitation of labelled antigens bound to specific antibodies $(12,13)$. The validity of the method in the present context is supported by the fact that increased precipitation of added ${ }^{125} \mathrm{I}$-octreotide was never observed in serum from normal or from acromegalic patients who had not received octreotide, or in the initial phase of the conventional subcutaneous treatment.

Furthermore, the bound labelled octreotide and lanreotide could be displaced by 'cold' octreotide as shown in Fig. 1a and b. A similar method with PEG separation was used for these in vitro displacements.

PEG separation was used also for estimation of crossreactivity in sera containing octreotide antibodies employing iodonated somatostatin, ${ }^{125} \mathrm{I}-\mathrm{Tyr}^{11}$-somatostatin-14 (Amersham International, Amersham, Bucks, UK) or ${ }^{125}$ I-lanreotide (Ipsen Biotech, Paris, France), labelled as described previously (14).

\section{Data analysis}

Comparison of patients with vs without octreotide antibodies, previously untreated vs previously treated patients and values before and after antibody formation was performed using Student's $t$-test (parametric data) or Mann-Whitney rank sum test (non-parametric data). Results were expressed as means \pm s.E.M. or as medians (10-90\% percentile). The analyses of local side effects were performed by using Chi-square and Fisher Exact test. A $P$ value $<0.05$ was considered statistically significant. We used the updated Sigma Stat (V.1.02) programme (1993 Jandel Scientific, Erkrath, Germany).

\section{Results}

The unspecific coprecipitation of ${ }^{125}$ I-octreotide in antibody-negative samples (controls) varied from batch to batch of label and with age of label, and was therefore determined at each set-up. It varied from $4.7 \% \pm 0.5 \%$ to $8.6 \% \pm 1.72 \%$ (S.D.).

In the antibody-positive patients the precipitation of ${ }^{125}$ I-octreotide varied from $6.6 \%$ to $90 \%$ (before subtraction of unspecific coprecipitation). The average value (at maximum level for any patient) was 32\%.

\section{Study 1 (nasally octreotide treated patients)}

Occurrence of antibodies Using the above definition, 39 out of 70 patients $(56 \%)$ developed antibodies in the previously untreated group, and 49 out of 81 patients $(61 \%)$ in the group previously treated with subcutaneous octreotide.

The occurrence of antibody formation increased with time. In the previously treated group the occurrence was as high as $81 \%$ (13 out of 16 patients) for those patients who completed the study. The corresponding occurrence for the previously untreated group was $77 \%$ (20 out of 26 patients). The temporal occurrence is illustrated in Fig. 2. Antibody formation occurred most frequently after 3 to 6 months.

Exposure time The total median octreotide exposure time for patients who developed antibodies on nasal treatment vs patients who did not was 274 (170-360) days vs $182(43-360)$ days $(P=0.001 ; n=151)$.

Dosage We did not find an unambiguous association between administered dose and antibody formation. Information about the dosages was available for 141/ 151 of the patients. There was an increasing tendency to antibody formation in patients treated within the range of $0.25 \mathrm{mg}$ to $1 \mathrm{mg}$. Seventeen out of 37 patients $(46 \%)$ treated with $0.25 \mathrm{mg}, 25 / 41$ (61\%) treated with $0.50 \mathrm{mg}$ and $26 / 32(81 \%)$ who received $1 \mathrm{mg}$ developed antibodies. Out of 31 patients treated with the $2 \mathrm{mg}$ dose, however, antibody formation occurred in 17 (55\%). Only $3 / 31$ patients in the $2 \mathrm{mg}$ population had previously been treated with s.c. octreotide, possibly explaining the relatively low percentage after treatment with this dose.

Efficacy There were no significant differences in serum IGF-I or GH levels (for patients in whom an unchanged dose allowed comparison) in the last sample before and the first sample after antibody development, as shown in Table 1.

\section{Study 2 (subcutaneously octreotide treated patients)}

Occurrence of antibodies and exposure time The overall occurrence of antibodies developed during subcutaneous octreotide treatment was 63 out of 231 patients $(27 \%)$ after a mean exposure time of $38 \pm 2.3$ months (means \pm s.E.M.). Antibody-positive patients had been exposed significantly longer to s.c. octreotide than antibody-negative patients, $58.5(15.8-106)$ vs 20.4 (1.2-71) months (median (10-90\% percentile) $(P<0.001)$. In patients treated for more than 2.5 years (means \pm S.E.M.: $5.7 \pm 0.2$ years) we found antibody 

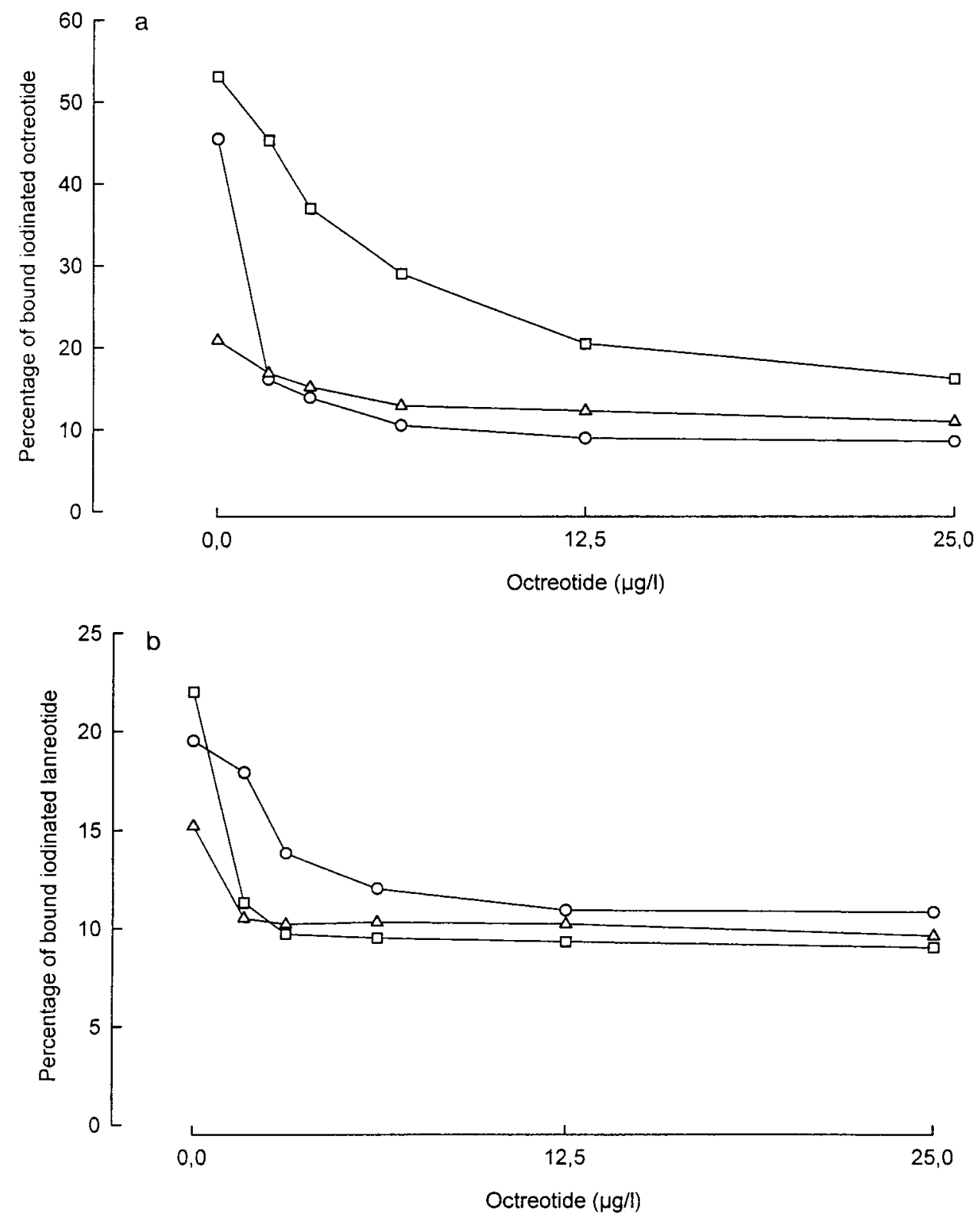

Figure 1 (a) Competitive reduction in antibody-bound ${ }^{125}$-labelled octreotide in sera of 3 antibody-positive patients by increasing amounts of unlabelled octreotide. Unspecific precipitation has not been subtracted. (b) Competitive reduction in antibody-bound ${ }^{125}$ I-labelled lanreotide in sera of 3 octreotide antibody-positive patients. Unspecific precipitation has not been subtracted.

formation in 37/106 (35\%) patients. The corresponding percentage of antibody occurrence after more than 5 years $(7.3 \pm 0.2$ years, means \pm S.E.M. $)$ was $57 \%(30 /$ 53 patients) and after more than 8 years treatment (means \pm s.E.M.: $9.1 \pm 0.3$ years $)$ was $72 \% \quad(13 / 18$ patients). The results obtained in the patients treated with subcutaneous octeotride in our clinic are shown in Fig. 3.

Dosage No significant difference was found between antibody-positive and antibody-negative patients with regard to the previous dosage (data not shown).
Efficacy As we were not able, in the majority of the acromegalic patients, to compare samples with those from before antibody formation, we judged efficacy by comparing GH and IGF-I concentrations while on s.c. treatment in antibody-positive and antibody-negative patients. This was possible since all patients who were screened before entering the European nasal trial were treated with the same s.c. dose $(100 \mu \mathrm{g}$ t.i.d.). There were no significant differences in IGF-I or GH values at screening or washout in antibody-positive versus antibody-negative patients, as shown in Table 2 . All values in Tables 1 and 2 are given as medians (10-90\% percentile). 


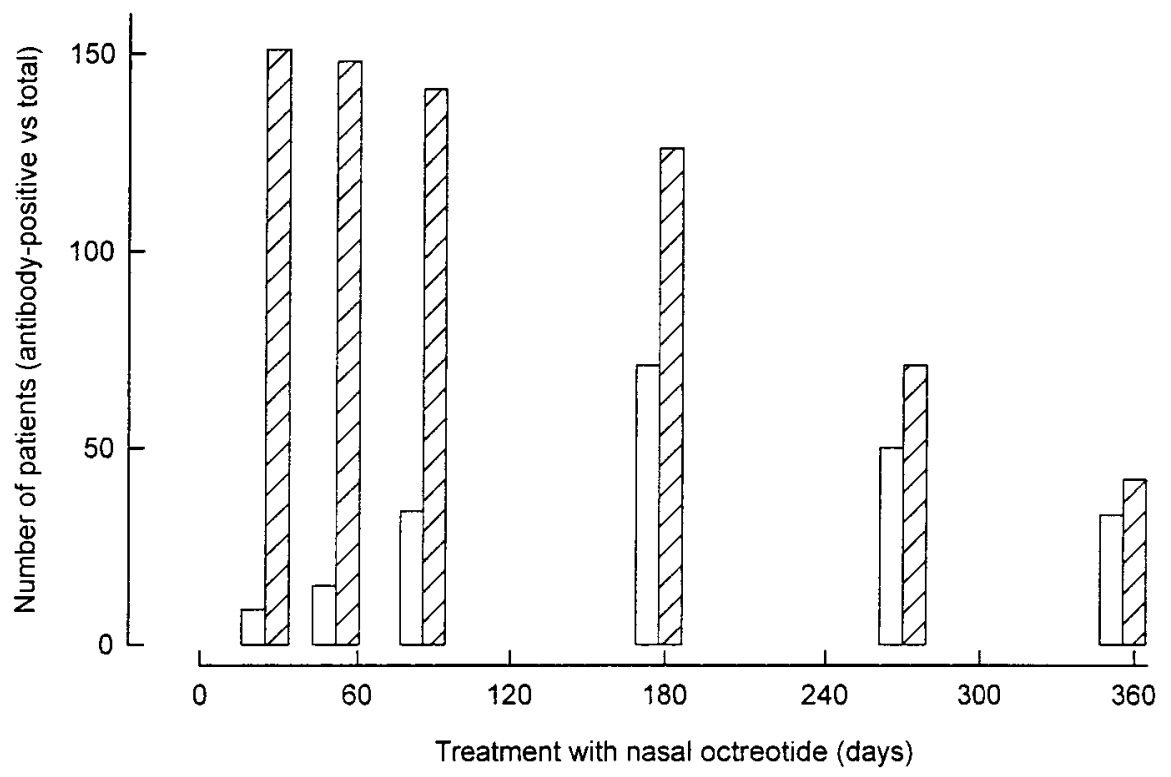

Figure 2 Number of antibody-positive patients (open bars) versus the total number of patients still participating in the nasal study (hatched bars) at days 14, 28, $43(56), 84$ (90), 182, 274 and 360 (study 1). The numbers in parentheses indicate that on these two occasions previously treated and untreated patients were studied at slightly different time points.

All carcinoid patients were clinically (diarrhoea and flushing) well controlled by s.c. octreotide. This was an inclusion criteria for entering the LAR study.

\section{Study 3 (intramuscularly microsphere encapsulated octreotide treated patients)}

Occurrence of antibodies and exposure time Three out of 47 patients $(6.4 \%)$, who did not harbour detectable antibodies in washout samples at baseline showed a very slight increase $(0.3-1.2 \%)$ of the binding percentage of ${ }^{125}$ I-octreotide after 6 intramuscular injections (after 8 months treatment). In these 3 patients the binding percentages were again normalized after the 19th injection (21 months treatment), possibly due to saturation of the weak antibodies with constantly high circulating levels of octreotide. We had no access to washout samples in these 3 patients after finishing the LAR study and therefore cannot conclude with certainty if they really had developed antibodies during LAR treatment.
These three patients had previously been treated for a mean of $50 \pm 24.7$ (range 24-99) months with s.c. octreotide.

None of the remaining 44 patients developed antibodies during up to 3 years treatment with Sandostatin LAR. They had been exposed to the LAR formulation during $29 \pm 1$ months ( $n=40$, data not available for 4 patients).

No patient in the selected previously untreated population $(n=24)$ developed antibodies during $33 \pm 0.4$ months treatment. All values are given as means \pm S.E.M.

Patients who already harboured antibodies at study entry $(n=15)$ still had antibodies at the end of the LAR trial and, as far as could be evaluated, without major changes in level. None of these patients had local or systemic tolerability problems.

As $7 / 14$ patients treated in our clinic with Sandostatin LAR were antibody-positive already at study entry, it was possible to compare GH and IGF-I concentrations in the two groups. As shown in Fig. 4, GH and IGF-I values were not significantly different,

Table 1 IGF-I (mean of 2 values) and GH changes (mean of 8 values after drug administration) in $\mu \mathrm{g} / \mathrm{l}$ before and after antibody formation in previously treated $(n=37)$ and previously untreated $(n=37)$ acromegalic patients in study 1 . Values are medians $(10-90 \%$ percentile).

\begin{tabular}{|c|c|c|c|c|c|c|}
\hline & \multicolumn{2}{|c|}{ IGF-I } & \multirow[b]{2}{*}{$\boldsymbol{P}$} & \multicolumn{2}{|c|}{ GH } & \multirow[b]{2}{*}{$\boldsymbol{P}$} \\
\hline & Before & After & & Before & After & \\
\hline Previously treated & $276(133-569)$ & $263(129-611)$ & 0.81 & $1.2(0.5-3.3)$ & $1.3(0.5-3.7)$ & 0.78 \\
\hline Previously untreated & 575 (180-1044) & 535 (161-926) & 0.54 & $4.0(0.9-13.2)$ & $4.6(0.9-16.2)$ & 0.99 \\
\hline
\end{tabular}


Table 2 IGF-I (mean 2 of values) and GH concentrations (mean of 8 values after drug administration) in $\mu \mathrm{g} / \mathrm{l}$ in antibody-positive ( $n=19)$ and antibody-negative patients $(n=68)$ at screening (on s.c. octreotide, study 2 ) and at washout before entering study 1 . Values are medians (10-90\% percentile).

\begin{tabular}{|c|c|c|c|c|c|c|}
\hline & \multicolumn{2}{|c|}{ IGF-I } & \multirow[b]{2}{*}{$P$} & \multicolumn{2}{|c|}{ GH } & \multirow[b]{2}{*}{$P$} \\
\hline & Antibody-positive & Antibody-negative & & Antibody-positive & Antibody-negative & \\
\hline Screening & $242(152-496)$ & $229(123-549)$ & 0.88 & $1.3(0.4-2.6)$ & $1.4(0.5-2.6)$ & 0.71 \\
\hline Washout & $567(293-903)$ & $538(314-806)$ & 0.97 & $4.1(2.4-16.0)$ & $5.9(3.0-19.3)$ & 0.19 \\
\hline
\end{tabular}
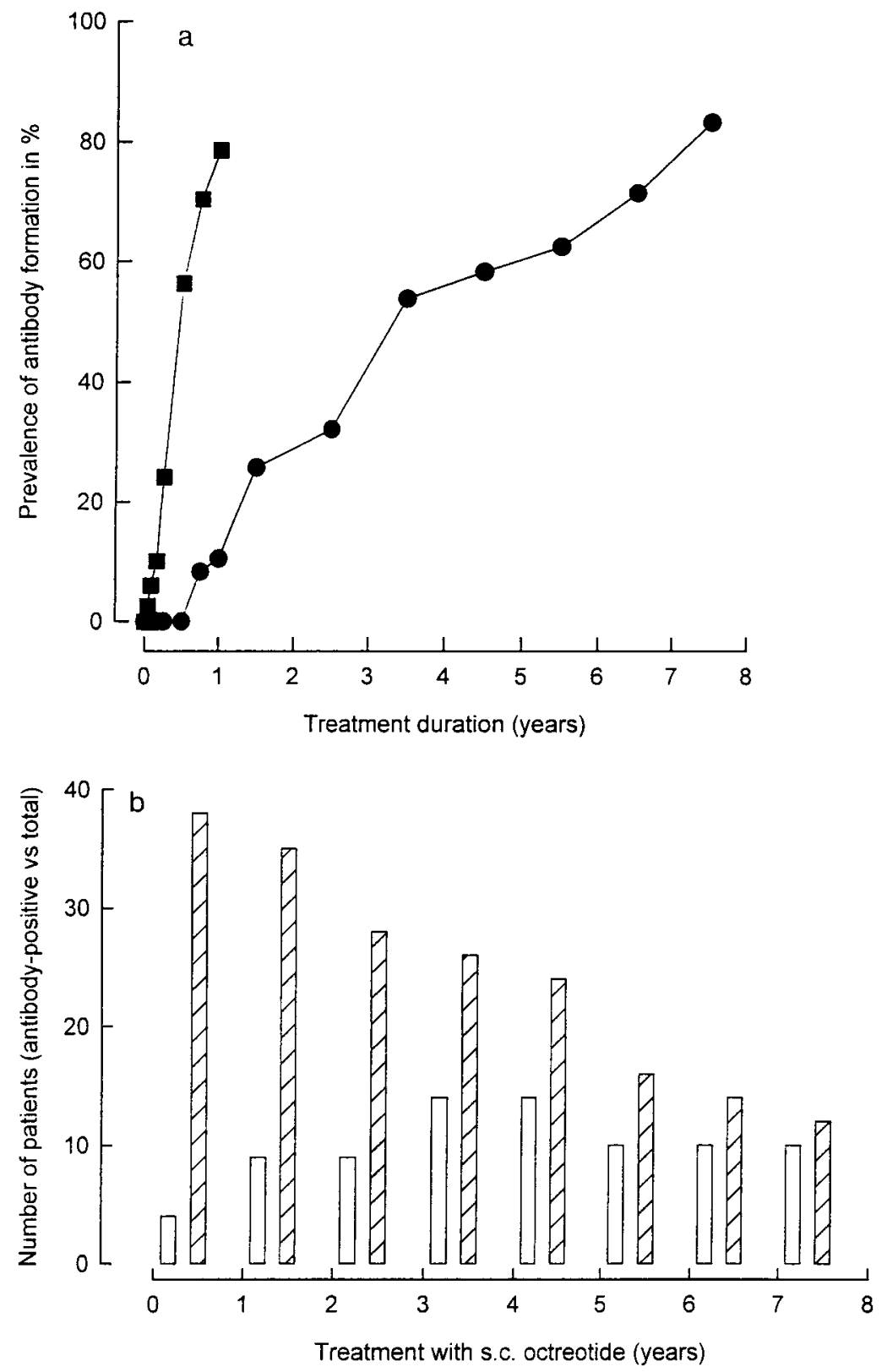

Figure 3 (a) Prevalence of antibody formation (as a percentage) during up to 8 years treatment with subcutaneous octreotide $(\bullet)$ in 38 acromegalic patients from our clinic (study 2) compared with the prevalence during up to 1 year of treatment with nasal octreotide (ם), $(n=151$, study 1$)$. (b) Number of antibodypositive patients (open bars) versus the total number of patients in subcutaneous octreotide treatment (hatched bars) in 38 acromegalic patients from our clinic (study 2). 

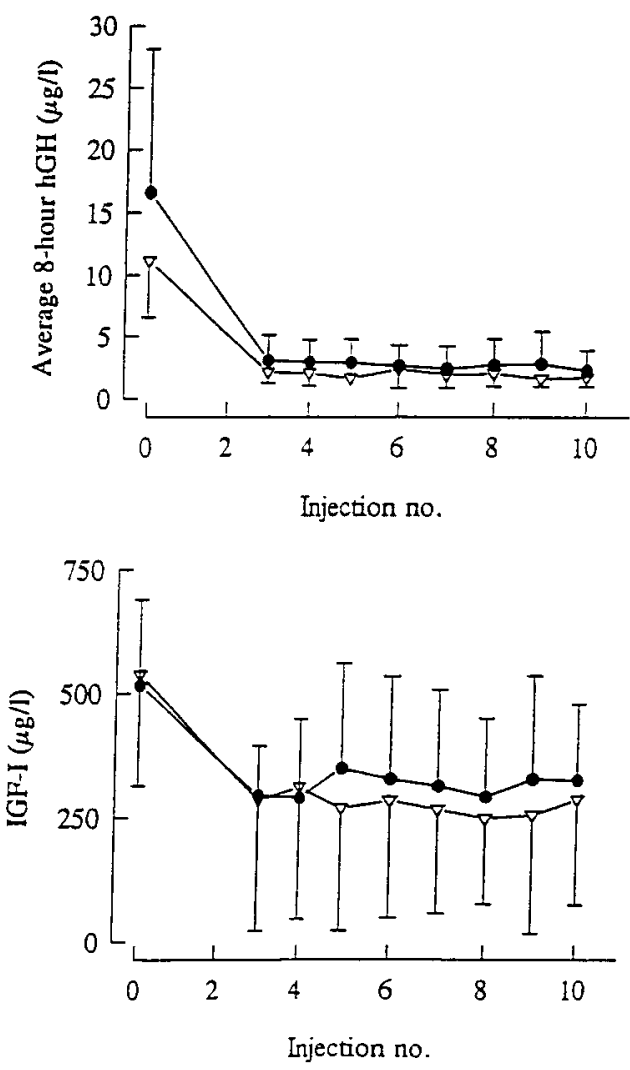

Figure 4 Comparison of average serum $\mathrm{GH}$ (mean of $8 \mathrm{~h} \pm$ s.D.) and IGF-I in 7 antibody-positive patients at entry $(\bullet)$ and 7 antibodynegative $(\nabla)$ patients at baseline (after 3 days washout) and 28 days after the 3rd (when in steady-state), 4th, 5th, 6th, 7th, 8th, 9th, and 10th injection of Sandostatin LAR. There was no significant difference in the administered dosage in the two populations (study 3).

neither were the administered dosages in the two populations. All patients were successfully treated.

Cross-reaction with somatostatin and another somatostatin analogue, lanreotide We examined morning serum samples from 141/151 patients with identified octreotide antibodies from the first two study populations (nasally and subcutaneously treated) from the study day at which the percentage of precipitated ${ }^{125}$ I-octreotide was highest, and found cross-reaction with labelled somatostatin in none.

One hundred and twenty-one of the antibody-positive sera were examined for cross-reaction with another labelled somatostatin analogue, ${ }^{125}$ I-lanreotide. We found 32/121 (26.4\%) certain cases of lanreotide cross-reaction (bound iodinated lanreotide $>5 \%$ ). Figure 5 shows the relationship between percentage of precipitated labelled lanreotide versus that of precipitated labelled octreotide. The precipitation activity in normal sera+3 S.D. is subtracted. However, attention should be paid to the fact that we did not measure the specific activity of either labelled analogue, i.e. the

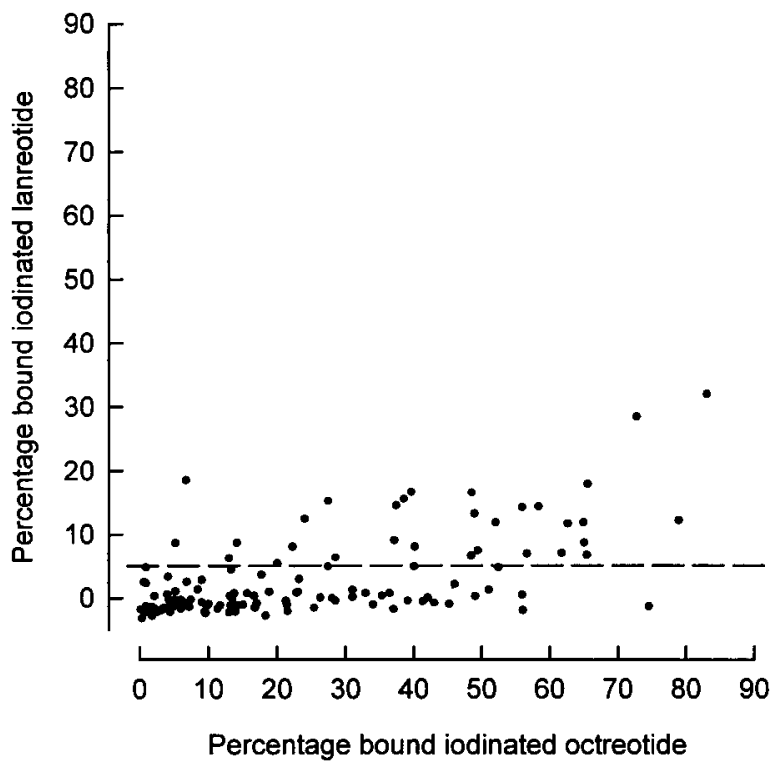

Figure 5 Percentages of bound ${ }^{125}$-lanreotide versus bound ${ }^{125}$ octreotide for 121 antibody-positive patients from studies 1 and 2 . The average precipitation per cent in control serum+3 s.D. was subtracted. The broken horizontal line marks the definition border for definite cross-reaction for lanreotide.

precipitated percentages are not directly comparable. However, it is still valid that about $25 \%$ of the sera cross-react.

Two of the patients whose sera cross-reacted had earlier been treated with a slow release formulation of lanreotide for 6 and 12 months respectively.

\section{Side effects}

Study 1 (nasally octreotide treated patients) Local symptoms (for example rhinitis, serous secretion and sneezing (up to 20 times in several patients after each sufflation)) were reported quite frequently by many investigators in the multicentre study. Seven out of 85 antibody-positive patients and 20 out of 59 antibodynegative patients had never had nasal symptoms throughout the study; this difference is significant $(P<0.003$, Chi-square test $)$. No systemic side effects which could be associated with antibody formation were observed.

Study 2 (subcutaneously octreotide treated patients) Side effects were sought in the patients treated in Denmark with subcutaneously administered octreotide. We observed no systemic effects in any patient which might be associated with immune reactions. However, in response to a questionnaire dealing with local side effects (specifically asking for local pain, erythema, swelling, indurations, lipoatrophy and paresthesias at the injection site) comprising 27 patients, one manifestation (indurations) turned out to 
Table 3 The occurrence of skin manifestations in antibodypostitive and antibody-negative patients in study 2 .

\begin{tabular}{lcc}
\hline & $\begin{array}{c}\text { Antibody-positive } \\
\text { patients }\end{array}$ & $\begin{array}{c}\text { Antibody-negative } \\
\text { patients }\end{array}$ \\
\hline + Indurations & 14 & 1 \\
- Indurations & 4 & 8 \\
\hline
\end{tabular}

$P=0.003$ (Fisher Exact Test).

be significantly more frequent in antibody-positive (14 out of 18) than in antibody-negative (1 out of 9 patients) (Table 3 ).

Study 3 (intramuscularly microsphere encapsulated octreotide treated patients) Antibody-positive patients (at entry), who were treated with intramuscularly administered depot octreotide, did not develop detectable indurations at the injection sites during LAR treatment.

\section{Discussion}

Antibody formation against octreotide is much more frequent than previously believed $(5-7,9,10)$. The occurrence depends on the exposure time to the drug and the route of administration. It is particularly pronounced with intranasal insufflation, by which the great majority of patients were antibody-positive within one year of treatment. Antibody appearance occurs much later in patients treated by the classical subcutaneous administration. Of note, it appears at present to be much rarer with the new microsphere enclosed formulation, Sandostatin LAR. We had the opportunity to study samples from 24 Romanian patients after the LAR study was closed; none was antibody-positive 62 days after the last LAR injection. This period may, however, be too short to exclude with certainty persistance of antibody saturation with octreotide. We have no definite explanation for these different occurrences with different octreotide administration forms. One suggestion may be that octreotide administered by the intranasal and subcutaneous route is, to a higher degree, removed from the administration site by lymph, while the slowly released octreotide from the intramuscular microspheres primarily diffuses into blood. A participating fact may be that the local interstitial octreotide concentrations fall drastically from nasal over subcutaneous to intramuscular application sites.

Furthermore, the galenic formulation of octreotide is different for the nasal route administration and for subcutaneous or intramuscular injection. The nasal powder contains Avicel as a carrier. It is possible that the carrier could play the role of an adjuvant leading to increased production of antibodies against octreotide. It must also be remembered that nasal octreotide insufflation in itself induces an epithelial swelling lasting one hour and a feeling of nasal stuffiness (15); this phenomenon may be involved in the high tendency to develop antibodies after nasal application.

The high incidence of nasal side effects in patients harbouring antibodies is probably an effect of local reactions between antigen and antibody. However, we cannot exclude the opposite association that patients with the more severe epithelial nasal reactions to octreotide are therefore more prone to develop antibodies.

In antibody-positive patients on subcutaneous treatment we observed a significantly increased appearance of indurations at injection sites. In a few cases these have been quite bothersome, eventually making it difficult for the patients to find injection sites that are not painful. No patient, however, has to our knowledge chosen to abstain from octreotide treatment for this reason. These cutaneous effects are in accordance with the local side effects previously described in two antibody-positive acromegalic patients $(5,7)$.

We have not been able to determine any side effects associated with the presence of antibodies in 7 antibody-positive patients (i.e. attained during previous s.c. or nasal treatment) while on intramuscularly administered octreotide (Sandostatin LAR). We have now confirmed in a large series of patients antibody-positive after subcutaneous treatment that antibodies do not cross-react with labelled somatostatin-14. But octreotide antibodies cross-reacted in at least $25 \%$ of the patients with another labelled octapeptide, the somatostatin analogue, lanreotide. In many cases there is a relationship between high percentages of bound labelled octreotide and bound labelled lanreotide. But in some cases even with high octreotide binding (>30\%) antibodies did not cross-react. It is interesting that such a small peptide as octreotide is capable of inducing antibodies directed at more than one epitope.

We have validated the PEG precipitation technique for determining the presence of octreotide antibodies in several ways. First, we obtained identical results using another classic technique for separation of free from antibody-bound antigens, namely charcoal (data not shown). Secondly, we demonstrated that labelled antibody-bound octreotide was displaced by unlabelled octreotide. Finally, we have never found antibodies in subjects not previously treated with octreotide. Note, however, that our assay possibly did not measure all anti-octreotide immunglobulins present in serum, since we used a tyrosyl-substituted octreotide analogue (which also contains a relatively large iodine molecule) for detection.

It is noteworthy that the long-term presence of octreotide antibodies induced no reduction in efficacy, i.e. in the suppressive effect on serum GH and IGF levels. This is probably due to the low affinity nature of human octreotide antibodies.

The presence of antibodies may, as shown previously, change the pharmacokinetics of octreotide due to a prolonged plasma elimination rate which causes a prolonged GH suppression after s.c. octreotide (6). 
In spite of the fact that octreotide antibodies have no serious adverse effects, the use of octreotide formulations of low antigenicity would seem desirable. Increasing use of the LAR preparation may diminish the incidence of octreotide antibodies.

\section{Acknowledgements}

This study was supported by grants from the Institute of Experimental Clinical Research and from the Faculty of Health Science, Aarhus University. Furthermore, the study was supported by the Danish Health Research Council, grant no. 9600822 (Aarhus University-Novo Nordisk Centre for Research in Growth and Regeneration). We are grateful to Ipsen Biotech, Copenhagen for supplying us with lanreotide for iodination. We are indebted to many people, especially Mrs A Pilling and Mr S Abeysinghe for tireless help during A Kaal's stay in the Sandoz Clinical Development Centre (Frimley, UK) when going through the patients' case records forms. We are indebted to Mrs K Nyborg Rasmussen, I Bisgaard, S Sørensen, N Rosenquist and K Matthiassen for skilled technical assistance.

\section{References}

1 Berson SA, Yalow RS, Bauman A, Rothschild MA \& Newerly K. Insulin $\mathrm{I}^{131}$ metabolism in human subjects. Demonstration of insulin binding immunglobulin in circulation of insulin treated subjects. Journal of Clinical Investigation 195635 170-190.

2 Kaplan SL, August GP, Blethen SL, Brown DR, Hintz RL, Johansen A et al. Clinical studies with recombinant-DNA-derived methionyl human growth hormone in growth hormone deficient children. Lancet 1986 i 697-700.

3 Bisset GW, Black A, Hilton PJ, Jones NF \& Montgomery M. Polyuria associated with an antibody to vasopressin. Clinical Science and Molelecular Medicine 197650 277-283.

4 Kurtz AB. Insulin antibodies. In Textbook of Diabetes, pp 397-406. Eds CJ Pickup \& G Williams. Oxford: Blackwell Scientific Publications, 1994.
5 Kendall-Taylor P, Chatterjee S, White MC, Harris MM, Davidson K, Besser GM \& Wass JAH. Octreotide. Lancet 1989 ii 859-860.

6 Ørskov H, Christensen SE, Weeke J, Kaal A \& Harris AG. Effects of antibodies against octreotide in two patients with acromegaly. Clinical Endocrinology 199134 395-398.

7 Kwekkeboom DJ, Assies J, Hofland LJ, Reubi JC, Lamberts SWJ \& Krenning EP. A case of antibody formation against octreotide visualized with ${ }^{111}$ In-octreotide scintigraphy. Clinical Endocrinology $199339239-244$.

8 Kaal A, Frystyk J, Skjærbæk C, Nielsen S, Jørgensen JO, Bruns C et al. Effects of intramuscular microsphere-encapsulated octreotide on serum growth hormone, insulin-like growth factors (IGFs), free IGFs, and IGF-binding proteins in acromegalic patients. Metabolism 199544 (Suppl 1) 6-14.

9 Fuessl HS, Domin J, Anderson JV \& Bloom SR. Chronic administration of the somatostatin analogue SMS 201-995 does not lead to antibody formation. Alimentary Pharmacology and Therapeutics 1987 1 45-50.

10 Van Liessum PA, Swinkels LM, Pieters GF, Ross AA, Smals AG, Benraad TJ et al. Lack of antibody formation during long-term treatment with the somatostatin analogue octreotide in acromegaly. Acta Endocrinologica 19903 309-312.

11 Frystyk J, Skjærbæk C, Dinesen B \& Ørskov H. Non-competitive time-resolved immunofluoremetric assays for determination of human insulin-like growth factor-I and -II. Growth Regulation 19955 169-176.

12 Desbuquois D \& Aurbach GD. Use of polyethylene glycol to separate free and antibody bound peptide hormones in radioimmunoassays. Journal of Clinical Endocrinology and Metabolism $197133732-738$.

13 Kurtz AB, Matthews JA, Mustaffa BE, Daggett PR \& Nabarro JDN. Decrease of antibodies to insulin, proinsulin and contaminating hormones after changing treatment from conventional beef to purified pork insulin. Diabetologia 198018 147-150.

14 Greenwood FC, Hunter WM \& Glover JS. The preparation of ${ }^{131} \mathrm{I}$ labelled human growth hormone of high specific radioactivity. Biochemical Journal 196389 114-123.

15 Weeke J, Christensen SE, Ørskov H, Kaal A, Mau Pedersen M, Illum $\mathrm{P}$ et al. A randomized comparison of intranasal and injectable octreotide administration in patients with acromegaly. Journal of Clinical Endocrinology and Metabolism 199275 163-169.

Received 4 February 2000

Accepted 22 May 2000 